\title{
MUSEOLOGIA, FEMINISMOS E SUAS ONDAS DE RENOVAÇÃO
}

\author{
Camila A. de Moraes Wichers'
}

\begin{abstract}
Resumo
Nesse texto parto da premissa de que a Museologia é um campo de estudos voltado à preservação das memórias para, a partir desse ponto, tecer elos entre esse campo e as lutas feministas. Busco apresentar as reciprocidades entre essas lutas e o ideário que convencionou-se denominar como Nova Museologia, Sociomuseologia ou Museologia Social, destacando que esses termos, assim como as denominadas ondas dos feminismos, mais do que marcar rupturas, operam como ondas de renovação da prática museológica.

Palavras-chave

Museologia - Gênero - Feminismo

- Mulheres - Museologia Social
\end{abstract}

\begin{abstract}
In this text I start from the premise that Museology is a field of studies that addresses the preservation of memories to, from that point, weave links between this field and feminist struggle. I seek to present the reciprocities between these struggles and the ideas called $\mathrm{New}$ Museology, Sociomuseology or Social Museology, emphasizing that these terms, as well as the waves of feminisms, rather than mark ruptures, operate as waves of renewal of museological practice.
\end{abstract}

\section{Keywords}

Museology - Gender - Feminism Women

\section{Introdução}

O gênero estrutura as relações sociais, estabelecendo hierarquias e legitimando opressões. Essa simples assertiva, uma constatação comum do pensamento feminista voltado a analisar a sociedade moderna ocidental, quando inserida nos debates acerca da Museologia como campo de estudos e de intervenção, nos remete à difíceis constatações e desafios de monta. Como os museus têm lidando com a questão do gênero? Mulheres e homens são representados de que forma nas instituições e ações culturais? Temos reiterado estereótipos de gênero ou construído plataformas emancipadoras? Como o nosso campo tem lidado com as desigualdades de gênero em termos de atuação profissional?

São muitas as indagações e muitos os caminhos possíveis de serem trilhados nesse texto. Dessa forma, escolhi trilhar um percurso pessoal na Museologia, tecendo uma rede de inspirações e referências que me movem a dialogar com as questões supramencionadas.

A alusão, no título do texto, às ondas de renovação, parte do trabalho "Ondas do Pensamento Museológico Brasileiro" de Manuelina Maria Duarte Cân-

I Professora adjunta no bacharelado em Museologia e no Programa de Pós-Graduação em Antropologia Social da Universidade Federal de Goiás. Email: camilamoraes@ufg.br 
dido (2000), que, por sua vez, se inspirou na obra Vagues². Nesse sentido, a ideia de ondas de renovação busca salientar "a noção do infindável e do movimento contínuo que a produção do conhecimento tem e a ideia de que o pensamento museológico passa sempre por ondas de renovação" (DUARTE CÂNDIDO, 2008: 54). Busco aproximar essa ideia de movimento contínuo para compreender a relação entre feminismos e Museologia, bem como examinar como essas ondas se misturam, se alimentam ou repelem.

Cabe salientar que minha inserção na Museologia tem sido inspirada nas ideias de fato museológico e de cadeia operatória museológica, permeadas pela responsabilidade de um exercício profissional voltado à lida com a memória. Compreendo que os processos de musealização "consolidam e enrijecem os papéis e lugares de mulheres e homens e de suas identidades nas dinâmicas de construção da memória (OLIVEIRA \& QUEIROZ, 20I7: 65), nesse sentido, as memórias silenciadas, negligenciadas e exiladas colocam-se como tema a ser problematizado pelo pensamento feminista. Destarte, autoras como Waldisa Rússio C. Guarnieri - que bem salientou o papel das utopias em nosso trabalho - e Cristina Bruno são retomadas no primeiro bloco desse texto, voltado a defender a ideia de que a Museologia se coloca como Pedagogia da Memória.

Em um segundo momento, as discussões deflagradas pelo movimento internacional pela Nova Museologia, Sociomuseologia e Museologia Social e, mais recentemente, as práticas comunitárias em memória e museus, são brevemente apresentadas, uma vez que tais movimentos possibilitam um diálogo frutífero entre o campo da Museologia e os feminismos.

As ondas do movimento feminista e uma tentativa preliminar no sentido de integrá-las à algumas referências acerca dos movimentos de renovação do pensamento museológico e, sobretudo, aos marcos do que podemos denominar como uma Museologia de Gênero e/ou Feminista são abordadas na terceira parte do texto.

Por fim, são tecidas considerações acerca dos desafios e possibilidades para uma museologia generificada e feminista.

\section{Museologia como pedagogia da memória}

A relação entre a Museologia, pensamento feminista e estudos de gênero pode ser mais bem compreendida a partir de um determinado olhar para o campo museal: a ideia de que a Museologia é um campo voltado ao trabalho com a memória.

Parto da premissa de Cristina Bruno de que a memória é a matéria prima a partir da qual a Museologia estabelece sua cadeia operatória de procedimentos técnicos e a sua função (BRUNO, 2000: II). Nesse sentido, existiria uma Pedagogia Museológica que tem se envolvido, de diferentes maneiras, com as sociedades ao longo dos tempos (BRUNO, 2006: 3-4).A observação, seleção, valorização, exposição e guarda de objetos, que distinguem as sociedades humanas desde milhares de anos, estariam na origem das ações, que na modernidade oci- 
Museologia, feminismos e suas ondas de renovação

dental, levaram ao colecionismo e ao surgimento dos museus (BRUNO, 2006).

A pedagogia museológica parte de uma relação especifica com a realidade, conceituada como fato museológico na obra de Waldisa Rússio C. Guarnieri:

Fato museológico é uma relação profunda entre o homem, sujeito que conhece, e o objeto, testemunho da realidade. Uma realidade da qual o homem também participa e sobre a qual ele tem o poder de agir, de exercer a sua ação modificadora" (RÚSSIO, 2010:204).

Quando a autora construiu esse conceito, optou pelo uso do masculino neutro, característica recorrente à época, que tem sido revista em estudos contemporâneos. Aida Rechena (20lI), em um trabalho precursor devotado a compreender as relações entre gênero e Sociomuseologia, traz importantes contribuições nesse sentido. Revisita, assim, o "ternário matricial da museologia”, utilizando, sobretudo, a interpretação do fato museológico de Mário Chagas e inserindo nesse "ternário" mudanças teóricas e metodológicas resultantes dos elementos definidores da Sociomuseologia.

$\mathrm{Na}$ Figura I, proponho uma reelaboração do fato museológico a partir de uma museologia feminista e generificada:

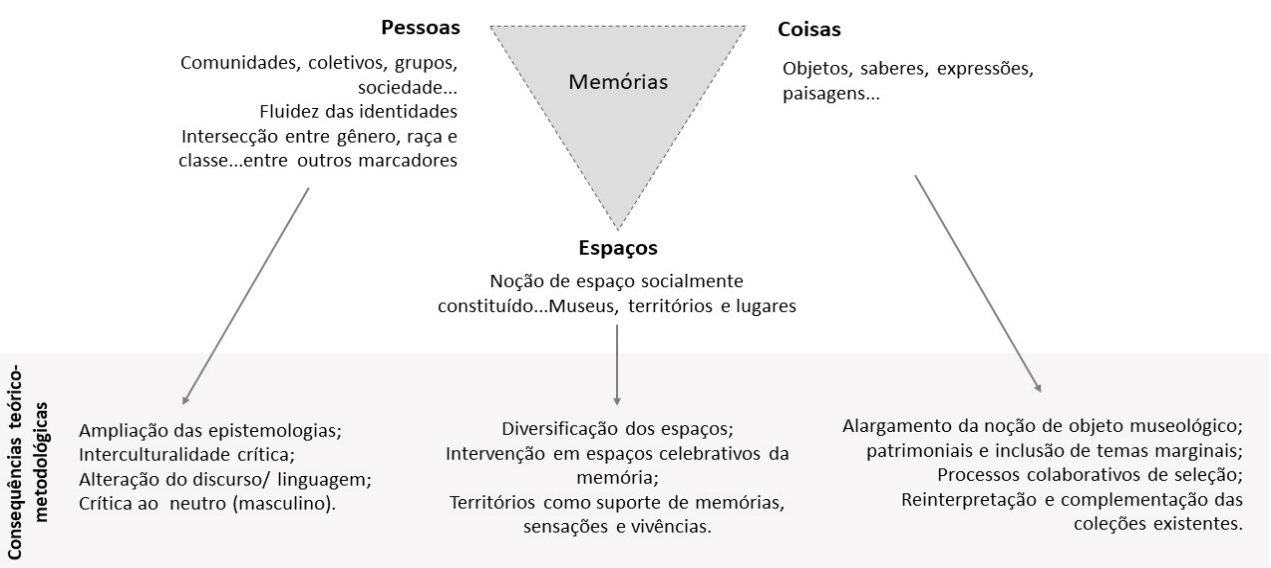

Figura 0 I. Fato museológico revisitado a partir de uma Museologia feminista e generificada. Organização da autora, com base em Rússio, 1984; Bruno, 1996, 2000; Duarte Cândido, 2000;

Chagas, 2008; Rechena, 201 I.

O fato museológico enfatiza a relação entre os elementos constituintes, aqui denominados como pessoas, coisas e espaços. Para Waldisa, essa relação pressupõe percepção, envolvimento e memória (RÚSSIO, 20I0). Cabe apontar que essa percepção, base da relação, envolve razão e emoção, o que nos aponta desde já um problema para epistemologia ocidental moderna, a qual valorizou sobremaneira a razão negando a emoção, como nos adverte Santos (2008). Devemos, pois, estimular a emoção como fator fundamental dessa relação.

A prática museológica envolve o estudo de todas as dimensões desse fato, mesmo que uma delas seja priorizada não temos como tratá-la de modo isolado, posto que o caráter relacional de nosso objeto de estudo está sempre presente. 
O componente humano, abordado a partir da noção de pessoa, deve ser considerado em si mesmo e para isso devemos estudá-lo em um nível psicológico, sociológico, político, histórico, etc. (RÚSSIO, 20I0). Esse componente é aqui entendido como as mulheres, homens, crianças, grupos, comunidades e sociedades. São as pessoas, coletivos e comunidades que estabelecem significados e atribuem valores à suas criações, selecionando as coisas que compõem essa relação.

Por objeto museológico entende-se as coisas, as paisagens, as experiências e referências culturais. A hierarquia de valores, apontada anteriormente, é que define quais desses objetos se tornarão patrimônio, envolvendo sempre uma seleção.

No pensamento de Waldisa Rússio (2010), essa relação profunda dependia do museu como agente de troca museológica. Não obstante, é cada vez mais frequente a compreensão de que essa relação pode se dar em qualquer espaço socialmente constituído, no museu, no centro de memória, na rua, na passeata, enfim, em qualquer lugar ou território.

Para Waldisa, o exercício da Museologia nos lançava a um papel de trabaIhador social, uma vez que esse trabalho "estaria ligado não somente ao cumprimento de uma função social, mas de quem trabalha de forma consciente com o social, colaborando para incutir ações de mudança” (BRUNO et al 2008: 32). À parte o emprego do masculino neutro, a refinada elaboração da autora nos mostra seu pioneirismo em articular a organização epistemológica da Museologia aos movimentos sociais, colocando-a como uma das precursoras, no Brasil, da Sociomuseologia (BRUNO et al 2008, pp.22-23).

Hernandez (2006) classifica como cognitiva a orientação oferecida pelo centro-leste europeu (com Zbyněk Zbyslav Stránský e Anna Gregorová, por exemplo) e como pragmática a contribuição de profissionais franceses e canadenses associados à emergência do movimento pela nova museologia. Nesse sentido, advogo que Waldisa Rússio C. Guarnieri articulou essas duas orientações - cognitiva e pragmática, de maneira inédita.

Em diálogo com essa forma de compreender o fato museológico, voltemos a alguns elementos da Pedagogia Museológica ou Educação da Memória. Essa pedagogia consistiria em um conjunto de procedimentos referentes à percepção e ao enquadramento dos indicadores da memória, a organização, tratamento e socialização dos suportes da memória, sendo decodificada, na contemporaneidade pelos estudos e práticas da disciplina Museologia,

\footnotetext{
Trata-se de uma pedagogia direcionada para a educação da memória a partir das referências patrimoniais que, por um lado, busca amparar do ponto de vista técnico os procedimentos museológicos e, por outro, procura ampliar as perspectivas de acessibilidade e problematizar as noções de pertencimento. É, portanto, um caminho permeado por experimentações, mas, especialmente, por análises críticas sobre a função social dos museus na atualidade. (BRUNO, 2006: 120 grifo meu).
}

Quando Cristina Bruno traz a ideia da educação da memória, não se trata 
Museologia, feminismos e suas ondas de renovação

de uma educação disciplinadora ou homogeneizadora, mas de uma educação que problematiza as memórias e as identidades no campo patrimonial e museológico e, sobretudo, de uma educação como ação transformadora por meio das experimentações próprias da cadeia operatória museológica. Essa noção do trabalho como transformador tem inspiração em Waldisa Rússio C. Guarnieri, conforme já pontuado.

A cadeia operatória museológica é formada por ações de salvaguarda (documentação e conservação) e comunicação museológica (exposições e ações educativas), cujo equilíbrio resulta na preservação dos indicadores da memória e referências patrimoniais. Um processo que pode diminuir os impactos do esquecimento. Aqui o sentido de preservação é pleno de possibilidades, pois emerge da premissa de que preservar é utilizar esses indicadores e referências para a construção de uma sociedade mais justa. Certamente, essas premissas encontram ecos nas lutas feministas.

Nesse percurso, a relação entre pedagogia museológica, construção da memória social e os feminismos coloca-se como caminho a ser desvelado. As representações marcadas nos museus e nos patrimônios são produtoras de memórias e esquecimentos, marcadas de fluidez e de dinamismo. São vetores e produtos de relações complexas, processos em curso, os quais podem e devem ser interpelados por uma crítica feminista da ciência (WYLIE, 20I4).

A substância da memória é tanto individual quanto social, como adverte Marilena Chauí: "o grupo retém e reforça as lembranças, mas o recordador, ao trabalhá-las, vai paulatinamente individualizando a memória comunitária" (CHAUÍ, 1987: XXX). A mesma autora, dialogando ainda com a obra seminal de Ecléa Bosi (1987), fala da opressão da memória, cuja ação mais sinistra seria a da "história oficial celebrativa cujo triunfalismo é a vitória do vencedor a pisotear a tradição dos vencidos” (CHAUÍ, 1987: XIX). Quem são os vencedores nas representações que acessamos nos museus e patrimônios?

Para Myrian Sepúlveda dos Santos (20I2), as representações coletivas podem ser responsáveis por processos de inclusão ou exclusão social, assim, a memória também é responsável pela imposição de coerções, exclusões e toda a sorte de controle social. A mesma autora evidencia que é necessário aceitarmos que existem diversas formas de lidar com o passado e que todas elas envolvem interesses, poder e exclusões.

Em alguns trabalhos, aparece uma distinção entre a memória que é transmitida oralmente entre gerações, denominada memória comunicativa, e a memória que é transmitida ao longo de séculos por meio de símbolos ou pontos fixos, a memória cultural. Essa última tem como especificidade o fazer lembrar a partir de pontos fixos, que representem um gatilho, como paisagens, objetos, livros, emblemas e monumentos (SANTOS, 20I3). Ora, as narrativas construídas a partir dos museus e patrimônios são compreendidas aqui como parte da memória cultural e, desse ponto de vista, participam ativamente nos processos de normatização ou emancipação de corpos e mentes.

Cristina Bruno (2005) tem utilizado o conceito de Memórias Exiladas para compreender a inserção dos vestígios arqueológicos na história social brasileira, que seria marcada por uma "estratigrafia do abandono". Penso que esse concei- 
to é extremamente profícuo para refletirmos acerca do exílio de outras memórias no campo dos museus e patrimônios. Para pensar nas memórias exiladas tomo um trecho de um texto magistral onde Lina Nochlin, onde ela se pergunta porque não existiram mulheres artistas.

(...) como todos sabemos, as coisas como estão, e como foram antes, nas artes e em centenas de outras áreas, são estupidificantes, opressivas e desestimulantes para todos aqueles que, como as mulheres, não tiveram a boa sorte de nascer brancos, preferencialmente de classe média e, sobretudo, homens. (NOCHLIN, 2017: 19)

Quando analisamos as memórias representadas nos museus a partir da interseção entre gênero, classe e raça, para mencionar apenas alguns marcadores sociais da diferença, observamos que as memórias de mulheres, sobretudo, as negras e indígenas, assim como as memórias de mulheres e homens que desafiam as normas de uma sociedade racista e heterocentrada, têm sido destinadas ao exílio ou à subalternidade. As memórias exiladas se referem aos silenciamentos e exclusões. As memórias subalternizadas são aquelas que estão nos espaços museais e de memória, mas a partir de representações frequentemente estereotipadas e marginais.

Para Stuart Hall (20l6), as representações são atos criativos que atuam na construção social da realidade. As representações estão relacionadas ao que as pessoas pensam sobre o mundo e sobre o que 'são' nesse mundo, guardando uma dimensão política. Assim, "não ter voz ou não se ver representado pode significar nada menos que opressão existencial” (ITUASSU, 20 I6, p. I3). Quando pesquisas instituições museológicas e de patrimônio constroem narrativas impregnadas de silenciamentos e de estereótipos das mulheres e outras minorias, acabam sujeitando-as a uma violência epistêmica.

\section{A Museologia e suas ondas de renovação}

Nas últimas décadas a Museologia tem passado por mudanças teórico-metodológicas significativas, desde a descentralização das ações museológicas, passando pelo alargamento da noção de patrimônio e chegando aos questionamentos acerca da função social dos museus e patrimônios. Uma das principais críticas feita a esse campo reside na necessidade de democratização não apenas do acesso, mas também da seleção e produção do patrimônio cultural. Como mencionado, o pensamento de Waldisa Rússio Camargo Guarnieri se insere na vanguarda desses processos no contexto brasileiro.

No Brasil, essas mudanças têm assumido diferentes nomenclaturas, como Nova Museologia, Sociomuseologia, Museologia Social e Museologia Comunitária, as quais expressam novos e diferentes enfoques sobre a abordagem do objeto de estudo da Museologia (MORAESWICHERS, 20I5). Esses enfoques também têm comum o deslocamento do trinômio Edifício-Coleção-Público para a tríade Território-Patrimônio-Comunidade, sendo que esse deslocamento pode assumir diferentes nuances, desde um museu tradicional que busca atuar em seu 
Museologia, feminismos e suas ondas de renovação

território de maneira mais inclusiva, até um museu que nasce de uma demanda comunitária. Conforme exposto na Figura I, essa ternário da Museologia, pode e de ser revisto a partir de um olhar generificado.

O termo Nova Museologia esteve associado, sobretudo, às discussões da década de 1980, fruto da reação dos museus e profissionais aos questionamentos colocados pelos movimentos sociais do final da década de 1960. Um processo onde a Mesa-Redonda de Santiago do Chile, sobre o papel social do museu na América Latina (1972), é considerada um marco importante. Esse termo estaria mais associado a um movimento que clamava por uma mudança de atitude do que por inovações teóricas e práticas (DUARTE CÂNDIDO, 2000)

A denominação Sociomuseologia, por sua vez, prioriza os contextos sociais onde a Museologia tem sido praticada, envolvendo interdisciplinaridade e um foco no desenvolvimento integrado (MOUTINHO, 2007). Em Portugal, o termo denomina um periódico e um programa de estudos pós-graduados ${ }^{3}$, sendo esses esforços resultantes também de um produtivo diálogo Brasil-Portugal.

Recentemente, o termo Museologia Social tem se consolidado no contexto brasileiro, se caracterizando pelos compromissos sociais que assume e com os quais se vincula, comprometendo-se com a redução das injustiças e desigualdades sociais, com o combate aos preconceitos e com a utilização do poder da memória (CHAGAS \& GOUVEIA, 20I5: 17).

Por seu turno, algumas pessoas têm utilizado o termo Museologia Comunitária, onde o pertencimento da/o pesquisadora à comunidade torna-se imperativo. Nesse contexto, cada pessoa aparece como elemento chave de uma Museologia que não constrói espaços onde a voz de quem fala é ocultada, mas sim, espaços que destacam o direito que têm os povos para falar de si mesmos, por si mesmos (LERSCH \& OCAMPO, 2004).

Para Jean Baptista e Claudia Feijó Silva (20 I3, p. I I), faz-se “necessário que as produções relacionadas à memória das comunidades sejam efetivamente realizadas a partir de relações de pertencimento com as mesmas". Nesse percurso propõem o termo práticas comunitárias e educativas em memória e Museologia Social, um campo dinâmico onde atuam perspectivas diversas, mas que partem da necessária intervenção das comunidades na seleção, produção, circulação e usos de seus patrimônios. Essas práticas não estão restritas aos processos que se autodenominam como museus comunitários, integrando experimentações e intervenções que têm na memória e no patrimônio uma ferramenta de luta para a valorização e visibilidade de memórias submetidas a contextos adversos que negligenciam os Direitos Humanos e Culturais (BAPTISTA \& SILVA, 20I3). Certamente, essas ideias encontram correspondências no movimento feminista. Entretanto, antes de propor algumas reflexões sobre as formas como as ondas de renovação da Museologia e do feminismo se retroalimentam, cabe retomarmos alguns elementos da trajetória do pensamento feminista.

3 Cadernos de Sociomuseologia, publicado desde 1993, sem dúvida, a mais importante publicação em língua portuguesa do campo da Museologia e Programa de Mestrado e de Doutorado em Museologia, na Universidade Lusófona de Humanidades e Tecnologias (ULHT), em Lisboa.A área da Museologia existe na ULHT desde I99I. 


\section{Os feminismos e suas ondas}

A despeito da diversidade de ideias, posturas e ações concernentes às ondas do movimento feminista, aqui compreendidas como extremamente fluídas, utilizarei essa forma de compreender a história do feminismo, com o intuito de traçar alguns paralelos com a Museologia, adiante.

Ainda que conte com antecedentes que chegam a cinco séculos, a chamada "primeira onda" do movimento feminista pode ser situada no século XIX, caracterizada por demandas de igualdade, emancipação e luta pelo direito ao voto.

Cabe apontar que esses movimentos tiveram certamente precedentes. Segundo Azadeh Kian, obras como a de Mary Wollstonecraft, "Reivindicação dos direitos da mulher", publicada em 1792, seria um dos textos fundadores do feminismo liberal ocidental. Não obstante, essas obras precursoras estariam marcadas por um olhar colonialista ao associar o Oriente com o despotismo e a tirania, entendendo o patriarcado como elemento oriental que deveria ser evacuado do Ocidente (KIAN, 20I0). Devemos lembrar que os museus estiveram estreitamente vinculados ao colonialismo e que o fato dos museus europeus - e brasileiros, estarem repletos de coleções saqueadas dos povos indígenas, não é neutro. No Brasil, o século XIX foi marcado por pesquisas associadas diretamente ao controle dos territórios e dos povos indígenas, a esses eram dadas duas alternativas: o controle e a normatização do Estado Imperial ou o extermínio. A colonialidade por trás dos objetos expostos em muitos museus é raramente problematizada nas exposições, ou seja, tratam-se de memórias exiladas.

Em 1949, Simone de Beauvoir publica "O segundo sexo". A partir de então, a assertiva de que "Ninguém nasce mulher, torna-se mulher" passaria a inspirar diversos estudos e ativismos, afirmando que a mulher é uma construção social e que a feminilidade é uma pretensão masculina para moldar as mulheres aos seus anseios.

Esses trabalhos, ainda que não utilizassem o termo gênero, partiam da ideia de um "sexo social" que influenciaria o feminismo de "segunda onda" - aquela que se inicia no final da década de 1960. Além das preocupações sociais e políticas, o feminismo irá se voltar para as construções propriamente teóricas. Surgem os estudos da mulher. No âmbito do debate que a partir de então se trava, entre estudiosas e militantes de um lado, e seus críticos ou suas críticas de outro, será engendrado e problematizado o conceito de gênero. A expressão "identidade de gênero" foi empregada pela primeira vez por Robert Stoller, um psicanalista norte-americano, como aponta Donna Haraway:

Ele formulou o conceito de identidade de gênero no quadro da distinção biologia/cultura, de tal modo que sexo estava vinculado à biologia (hormônios, genes, sistema nervoso, morfologia) e gênero à cultura (psicologia, sociologia). $O$ produto do trabalho da cultura sobrea biologia era o centro, a pessoa produzida pelo gênero - um homem ou uma mulher (HARAWAY, 2004: 216) 
Museologia, feminismos e suas ondas de renovação

Esse conceito foi ampliado por autoras feministas, destacando-se Gayle Rubin e seu "Tráfico de mulheres: notas sobre a 'economia política' do sexo" (1975), texto seminal onde a autora propõe que a divisão entre os sexos e a subordinação das mulheres são resultantes do sistema de sexo/gênero.

Temos as críticas a uma visão homogeneizadora do feminino e do masculino, que marcaram a 'terceira onda' do feminismo, surgida nas décadas de 1980 e 1990, com o questionamento da categoria mulher e pela desconstrução do sujeito feminino.

Podemos ressaltar os feminismos negros - nascido na segunda onda, mas expandido e fortalecido nas décadas subsequentes, com destaque para a obra de Angela Davis (2016, 2017); os feminismos lesbianos, sendo possível mencionar dentre muitas autoras, os escritos de Adrienne Rich, Audre Lorde e Gloria Anzaldúa (LORDE, 2007; RICH, 20I0;ANZALDÚA, 20I7), sendo frequente nesses escritos também a questão da interseccionalidade; os diálogos com a Teoria Queer, nos quais desponta a obra de Judith Butler (2013), e o "ciberfeminismo" de Donna Haraway (2009). Algumas autoras compreendem que os feminismos desconstrutivistas seriam nas realidade "pós-feminismos", dando lugar a uma quarta onda, nesse quadro estaria inserido o "feminismo queer". No Brasil, autoras como Guacira Lopes Louro e Berenice Bento - essa última com a proposta dos "estudos transviados" - têm trazido colaborações de monta para essas discussões (LOURO, 1997, 2004; RODRIGUES, 2005).

Penso que o feminismo intersecional, que tem se ampliado no contexto contemporâneo, é extremamente profícuo para pensarmos os processos de musealização e as memórias. Esse feminismo é fruto do pensamento precursor de mulheres negras que passaram a interpelar as reflexões de um movimento feminista que era pautado, até então, em demandas de mulheres brancas de classe média. $O$ termo intersecionalidade é assim definido por Kimberlé Crenshaw:

\footnotetext{
A visão de que as mulheres experimentam a opressão em configurações variadas e em diferentes graus de intensidade. Padrões culturais de opressão não só estão interligados, mas também estão unidos e influenciados pelos sistemas intersecionais da sociedade. Exemplos disso incluem: raça, gênero, classe, capacidades físicas/ mentais e etnia (CRENSHAW Apud VIDAL, 20I4: I).
}

Esse movimento tem buscado evidenciar que o feminismo, nas palavras de Ava Vidal "é excessivamente branco, classe média, cisgênero e capacitista (...) e não reflete sobre as experiências de diferentes mulheres, que enfrentam múltiplas facetas e camadas presentes em suas vidas" (VIDAL, 20I4).

Dessa forma, é possível afirmar que em suas ondas de renovação os feminismos não abandonaram uma crítica frontal à opressão das mulheres. Contudo, cada vez mais, o caráter extremamente diversificado da categoria mulher e a necessidade de uma abordagem intersecional ganham espaço. 


\section{Pensamento museológico e pensamento feminista: quando as ondas} se encontram

No que concerne aos museus, a primeira onda feminista esteve associada a diversas ações de protesto de mulheres sufragistas, como nos informa a obra de Carla Zaccagnini:"Elementos de beleza" (Figura 02). Essa obra e livro da artista, lançados em 20 I2, trazem as ações das sufragistas de Londres e Manchester, nos anos 1910, em museus (PACHELLA, 2015).

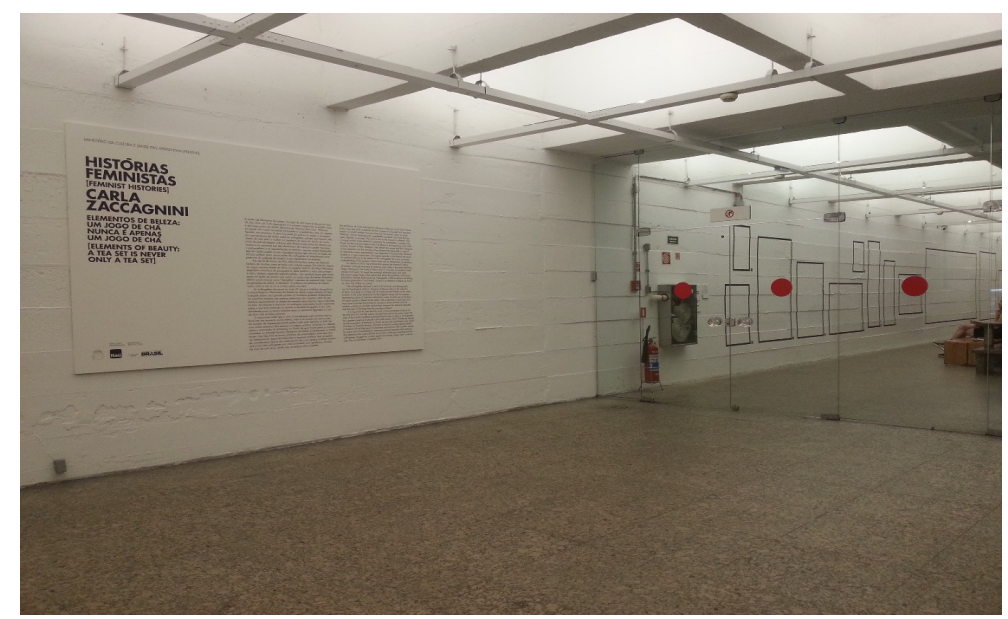

Figura 02. Histórias feministas, exposição de Carla Zaccagnini no Museu de Arte de São Paulo (MASP) em 2015. As molduras vazias simbolizam as obras nas quais as sufragistas interviram em protesto, sendo acompanhadas de um áudio com as histórias correspondentes. Foto da autora.

A obra foi inspirada em material de arquivo, fotografias, recortes de jornal e registros criminais a respeito da seção considerada mais radical do movimento, que defendia o direito de voto para as mulheres nas eleições políticas. A Women's Social and Political Union (WSPU), organização de militância pelo voto feminino, era adepta de táticas de ação não convencionais, que incluíam ataques a vitrines de lojas, museus e pinturas, em especial aquelas que representavam nus femininos e retratos de homens. Dessa forma, já na primeira onda do feminismo, os museus foram interpelados.

No que concerne à segunda onda, cabe pontuar que, na década de 1960, os museus foram fortemente questionados por seu caráter enciclopédico e elitista.As mudanças esboçadas anteriormente, sob a rubrica de um movimento internacional pela Nova Museologia podem ser compreendidas como respostas a esses questionamentos. Dessa forma, se a primeira onda do feminismo chegou em esparsas e pontuais vogas, a segunda onda assolou muitas das certezas anteriormente construídas.

Não obstante, essas ondas encontram espaços por vezes rígidos como rochedos, os quais se fecharam para reflexões propriamente feministas. Mais uma vez trago o trabalho de Aida Rechena para elucidar esse ponto:

As pessoas apesar de consideradas pela Sociomuseologia como sujeitos ativos na relação com o patrimônio ficam diluídas numa neutralidade uniformizadora que tendencialmente obscurece as 
mulheres ao equiparar o neutro universal com o masculino e a masculinidade. Entendida como uma categoria determinante das relações de poder e que se interseta com outras categorias sociais como a classe, a raça/etnia e a idade, o gênero provoca uma alteração do corpus teórico e da metodologia e o alargamento do campo de estudo nas ciências que $o$ incorporam, ao multiplicar as abordagens e as dimensões da investigação (RECHENA, 20ll:2l)

Ainda que a autora utilize o termo Sociomuseologia, pode-se aventar que as museologias renovadas, denominadas também como Nova Museologia e Museologia Social, muitas vezes deixam as opressões de gênero em um lugar à parte. Outrossim, embora haja uma potência entre as lutas travadas pela Nova Museologia e os Feminismos, ainda estamos construindo pontes.

Enquanto a terceira onda do feminismo trazia questionamentos acerca da categoria mulher, denunciando a intersecção de diversos marcadores sociais nas opressões de gênero, são iniciados os primeiros debates feministas na Museologia. Esses debates aparecem sob a roupagem dos "museus de mulheres", como se vê no número da revista Museum International, do Conselho Internacional de Museus (ICOM), com o título "Women in museum" (Mulheres nos museus), publicado em 1991. Irene Vaquinhas (2014), aponta ainda que, na década de 1990, existiu uma expansão dos museus de mulheres, sendo que o primeiro deles foi criado na Alemanha, em 198I.

Apenas no século $X X I$, vemos o uso alargado do conceito de gênero nos trabalhos que buscam debater essas questões nos museus, sendo, mais uma vez, a revista Museum International, do Conselho Internacional de Museus (ICOM), um termômetro dessas mudanças, com o número título "Gender Perspectives" (Perspectivas de Gênero), publicado em 2007.

A Figura 3 sintetiza algumas referências acerca das pontes entre práxis museológica e feminismos. Não tenho a pretensão de que essas referências sejam exaustivas, dando conta das diversas contribuições para esse diálogo, mas penso que eles podem nos ajudar as ver como as ondas feministas têm atingido e sido recebidas pela Museologia.

Ainda que marcada por reflexões teóricas e experiências inspiradoras, algumas tecidas brevemente desde o início desse texto, a Museologia Brasileira tardou em traçar pontes propriamente ditas com os feminismos. Sufocadas por décadas de ditadura militar, nós mulheres fomos paulatinamente nos inserindo no exercício profissional nos museus, mas as amarras da colonialidade do saber e do poder provocou fossos entre nossas práticas e a luta pelo fim da opressão causada pelas hierarquias de gênero.

Exemplos isolados, como o de Bertha Lutz, política, feminista e profissional de museu, certamente existiram, mas são ainda pouco estudados e conhecidos (LOPES, 2006). Contudo, as experiências vivenciadas até o século $X X I$ não integraram um olhar voltado especificamente para as questões de gênero, intersecionado com a sexualidade, a raça/etnia e a classe, entre outros marcadores. 


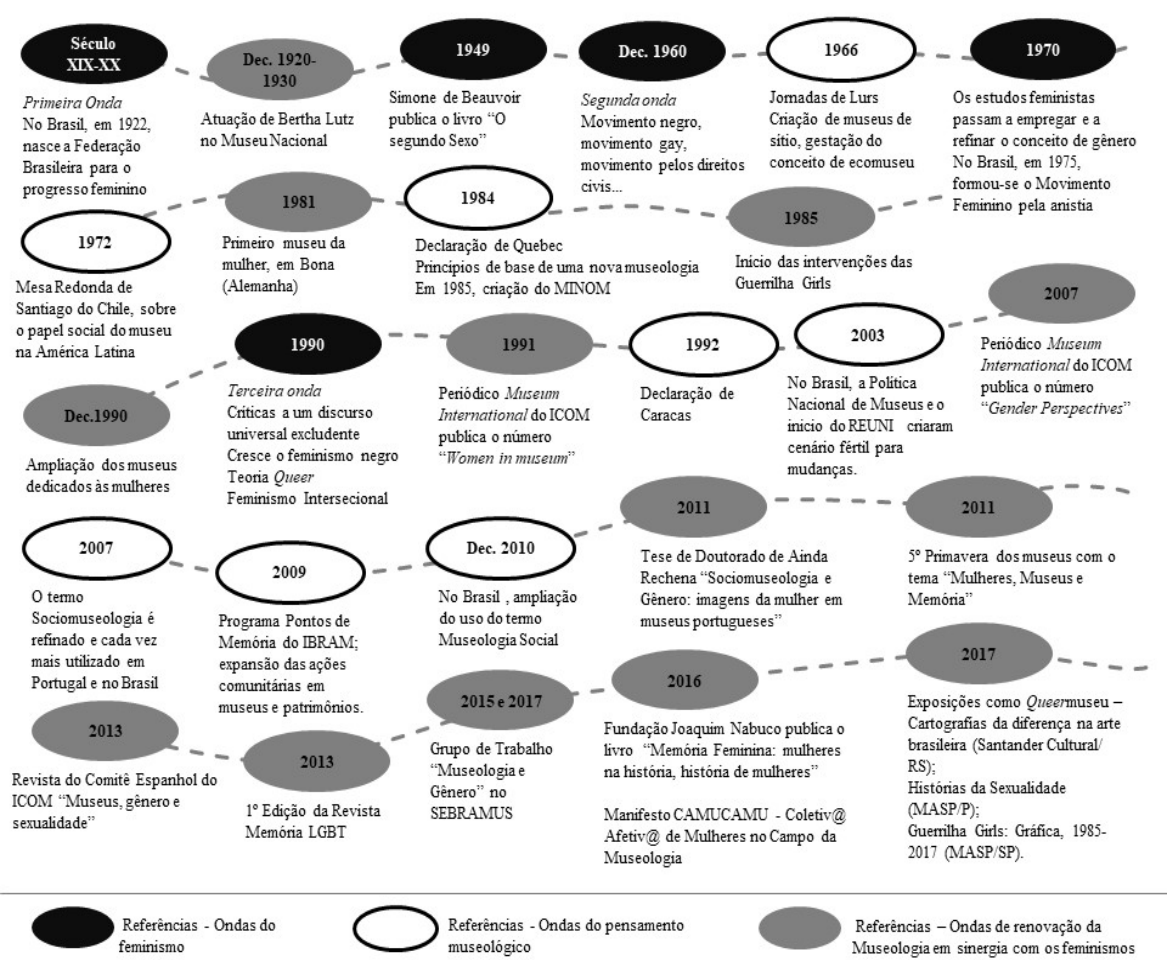

Figura 03. Esquema com marcos da relação entre pensamento museológico e feminismos

No início do século XXI, a Política Nacional de Museus e o programa de Restruturação e Expansão das Universidades Federais (REUNI), criaram um cenário fértil para a ampliação dos debates acerca da democratização das memórias, entre elas, as memórias das mulheres e outras minorias. Por um lado, a Política Nacional de Museus enfatizou o poder da memória em ações inovadoras como o Programa Pontos de Memória, por outro, o REUNI resultou em uma verdadeira revolução no ensino superior, sobretudo, quando vemos que os cursos de graduação em Museologia vivenciaram um crescimento exponencial.

Atuando em um desses cursos, tenho presenciado a força de uma práxis museológica que, guiada pelas utopias - como propôs Waldisa, parte de um determinado lugar de fala. Estou me referindo ao fato de que nunca se viu na Museologia um conjunto tão diversificado de mulheres, com trajetórias de luta e superação distintas, as quais têm impresso em seus trabalhos esse lugar de fala. Esses espaços de formação, assim como os museus comunitários colocam-se como oportunidades para a construção de processos mnemônicos emancipadores. Como afirmam Ana Audebert Oliveira e Marijara Queiroz:

\footnotetext{
Enquanto nos museus tradicionais as coleções tendem a referenciar a mulher branca, abastada, cristã, católica e bem casada, nos museus de territórios de favelas e regiões periféricas, sobressaem as mulheres negras com toda a carga histórica de exclusão, subordinação e inferiorização, mas também de resistências, de combates e de conquistas mais associadas à vida cotidiana (OLIVEIRA \& QUEIROZ, 2017:74)
}

Se o museu convencional raramente tem se aberto para essas questões, os processos comunitários são responsáveis por fortes e constantes ondas de 
Museologia, feminismos e suas ondas de renovação

renovação. E, cada vez mais, essas comunidades contarão com museólogas pertencentes a esses contextos.

Em 20II, podemos destacar o tema “Mulheres, Museus e Memórias”, escolhido para a $5^{\circ}$ Primavera de Museus. Nessa década vivenciamos avanços de monta, como a realização de grupos de trabalho no Seminário Brasileiro de Museologia, nos anos de 2015 e 2017. Por outro lado, experenciamos o recrudescimento de uma agenda conservadora, que atacou exposições como a Queermuseu. Importante assinalar como essas ações focaram especialmente espaços de representação onde gênero e sexualidade se entrelaçaram. Nesse sentido, as alianças entre movimento feminista e LGBT também se fizeram sentir - não sem resistências de segmentos desses movimentos, alimentando-se da construção teórica, metodológica e política de uma museologia voltadas às memórias LGBT (BOITA, 20I4; BAPTISTA \& BOITA, 20I7).

Conforme esboçado, há uma potência no diálogo entre um pensamento museológico progressista, voltado a práticas emancipadoras, e o pensamento feminista. As seções anteriores buscaram evidenciar a diversidade de abordagens em ambos os campos, sendo importante destacar que

um dos papéis fundamentais da Museologia Social é procurar entender, discutir e agir coletivamente contra as imposições e opressões da sociedade. Nesse sentido, evidenciar as mulheres, suas memórias e suas diferentes vozes, contribuir com a conscientização das diversas formas de opressão sofridas pelas mulheres bem como estimular o protagonismo feminino e a visibilidade das mulheres na sociedade e no campo da museologia são nossas demandas iniciais (...) (CAMUCAMU, 2016).

O trecho acima, retirado da carta assinada, em setembro de 2016 ,pelo CAMUCAMU - Coletiv@Afetiv@ de Mulheres do Campo da Museologia, direcionadas à direção do Movimento Internacional pela Nova Museologia (MINOM), hoje um dos comitês do ICOM, aponta que se a Museologia Social busca realmente lutar contra as opressões, não pode se apartar da luta pelo fim das hierarquias de gênero.

\section{Considerações finais}

Somos herdeiras de práticas colonialistas, de coleções que são espólios, de museus que tendem a manter nossas memórias exiladas ou subalternizadas. Mas também herdamos as conquistas das profissionais que nos precederam, as quais ao ser articuladas às premissas e lutas feministas podem construir novos futuros.

Da mesma forma em que as ondas de renovação não cessam de influenciar os percursos da prática museológica, o feminismo também tem sido transformado por incessantes ondas de renovação, trazendo questionamentos e possibilidades para uma prática feminista efetivamente emancipadora.

Defendo que as ondas dos feminismos e as ondas de renovação da Museologia 
se retroalimentaram, ainda que tardiamente, potencializando os elos entre um novo fazer museal, pautado no social, e uma busca árdua pela eliminação das desigualdades resultantes do sistema sexo/gênero.

Ao meu ver, é nas práticas comunitárias e educativas em memória e Museologia Social que temos uma plataforma onde a intervenção museológica tem a potência articular uma fala em primeira pessoa com a luta por reversibilidade de memórias exiladas e subalternizadas, em articulação com o movimento feminista intersecional.

\section{Referências}

ANZALDÚA, Gloria. Queer(izar) a escritora - Loca, escritora y chicana. In: BRANDÃO, I.; CAVALCANTI, I.; LIMA COSTA, C. da; LIMA,A. C.A. Traduções da Cultura. Perspectivas críticas feministas (1970-20I0). Florianópolis, EDUFAL, Editora da UFSC, PP 408-425, 2017. Publicado original em 1991

ASSIS, Maria Elisabete Arruda de; SANTOS, Taís Valente dos (Orgs.) Memória feminina: mulheres na história, história de mulheres. Recife: Fundação Joaquim Nabuco, Editora Massangana, 2016

BAPTISTA, Jean \& BOITA, Tony. Memória e esquecimento LGBT nos Museus, Patrimônios e espaços de Memória no Brasil. Revista do Centro de Pesquisa e Formação, $\mathrm{n}^{\circ}$ 5, pp.108-119, 2017.

BAPTISTA, Jean \& SILVA, Cláudia Feijó da (Orgs). Práticas comunitárias e educativas em memória e museologia social. Rio Grande: FURG, 2013.

BOITA, Tony. Memória LGBT: mapeamento e musealização em Revista. Monografia de conclusão de curso de Museologia. Universidade Federal de Goiás, 2014.

BOSI, Eclea. Memória e Sociedade: lembrança de velhos. São Paulo: Editora da Universidade de São Paulo, 1987.

BRUNO, Maria Cristina Oliveira. A luta pela Perseguição ao Abandono. Tese - FFLCH/USP para obtenção do título de livre-docente, São Paulo, 2000.

Arqueologia e Antropofagia:A musealização de sítios arqueológicos. Revista do Patrimônio Histórico Artístico Nacional, n³ I, pp. 234-247, 2005.

Museus e pedagogia museológica: os caminhos para a administração dos indicadores da memória. IN: MILDER, Saul E.S. As várias faces do patrimônio. Santa Maria: Pallotti, pp. I I9-I40, 2006.

BRUNO, Maria Cristina Oliveira., FONSECA, Andrea Matos da., \& NEVES, Kátia Regina Felipini. Mudança Social e Desenvolvimento no Pensamento de Waldisa Rússio Camargo Guarnieri: textos e contextos. IN: BRUNO, Maria Cristina Oliveira \& NEVES, Kátia Regina Felipini. Museus como Agentes de mudança social e desenvolvimento: propostas e reflexões museológicas. São Cristóvão: Museu de Arqueologia de Xingó, pp. 2 I-39, 2008.

BUTLER, J. P. Problemas de gênero: feminismo e subversão da identidade. Rio de Janeiro, Civilização Brasileira, 2003. Publicado original 1990.

CAMUCAMU. Territórios Afetivos das Mulheres do Campo da Museologia. Manifesto do Coletiv@Afetiv@ de Mulheres do Campo da Museologia, I5 de setembro de 2016. Disponível em https://labdobemviver.wordpress.com/2016/09/15/manifesto-camuca- 
Museologia, feminismos e suas ondas de renovação

mul Acessado em 15 de janeiro de 2018.

CHAGAS, Mário \& GOUVEIA Inês. (Orgs). Dossiê Museologia Social. Cadernos do CEOM. v. 27, n. 4I, 20l4. Disponível em https://bibliotextos.files.wordpress.com/201 I//2/o-conceito-de-museu-comunitc3al rio.pdf Acessado em I3 de janeiro de 2015.

CHAUÍ, Marilena. Os trabalhos da memória. IN: BOSI, ECLEA. Memória e Sociedade: lembrança de velhos. São Paulo: Editora da Universidade de São Paulo, pp. XVII-XXXII, 1987.

DAVIS, Angela. Mulheres, cultura e política. São Paulo, Boitempo, 20I7. Publicado original 1984.

Mulheres, raça e classe. São Paulo, Boitempo, 2016. Publicado original I98I

DESVALLÉES, André (Org). Vagues, une anthologie de la nouvelle muséologie, Mâcon, éditions W, Savigny-le-Temple, M.N.E.S, vol. I, 1992

. Vagues, une anthologie de la nouvelle muséologie, Mâcon, éditions W, Savigny-le-Temple, M.N.E.S, vol. 2, 1994

DUARTE CÂNDIDO, Manuelina Maria. Ondas do pensamento museológico brasileiro. Trabalho de Conclusão do Curso de Especialização em Museologia apresentado ao Museu de Arqueologia e Etnologia da Universidade de São Paulo, São Paulo, 2000.

. Ondas do pensamento museológico brasileiro. Balanço sobre a produção brasileira. IN: BRUNO, Maria Cristina Oliveira \& NEVES, Kátia Regina Felipini. Museus como Agentes de mudança social e desenvolvimento: propostas e reflexões museológicas. São Cristóvão: Museu de Arqueologia de Xingó, pp. 53-72, 2008.

GUERRILHA GIRLS. Guerrilha Girls: Gráfica 1985-201 7. Catálogo da Exposição realizada no MAM de São Paulo de 29/09/2017 a 14/04/2018.

HALL, Stuart. Cultura e Representação. Rio de Janeiro: Ed. PUC-Rio, Apicuri, 2016.

HARAWAY, Donna. "Gênero" para um dicionário marxista: a política sexual de uma palavra. Cadernos Pagu (22), pp.20I-246, 2004. Publicado original I 985.

. Manifesto ciborgue. Ciência, tecnologia e feminismo-socialista no final do século XX. IN: SILVA, T.T. da; KUNZRU, H.; HARAWAY, D. (Orgs). Antropologia do ciborgue: as vertigens do pós-humano. Belo Horizonte, Autêntica Editora, pp. 33-I I 8, 2009. Publicado Original 1991.

HERNÁNDEZ, Francisca Hernández. Planteamientos teóricos de la museología. Gijón: Ediciones Trea, 2006.

ICOM ESPANHA. Revista do Comitê Espanhol do ICOM, "Museos, género y sexualidade”, No. 8,2013

ICOM. Museum International - Revista do Conselho Internacional de Museus (ICOM), "Women in museum", Volume 43, No. 3, 1991.

- Revista do Conselho Internacional de Museus (ICOM), "Gender Perspectives",Volume 59, No. 4, 2007.

ITUASSU, Arthur. “Hall, comunicação e política do real”. In: HALL, Stuart. Cultura e Representação. Rio de Janeiro: PUC-Rio, Apicuri, Pp.9-13, 2006.

KIAN, Azadeh. Introduction: genre et perspectives post/dé-coloniales. Lescahiersdu CE- 
DREF - Centre d'enseignement, d'études et de recherchespourlesétudesféministes. v. I7, pP I8,2010 .

LERSCH, Teresa Morales \& OCAMPO, Cuauhtémoc C. O conceito de museu comunitário: história vivida ou memória para transformar a história? Conferência Nacional de la Asociación Nacional de Artes y Cultura Latinas, Kansas City, Missouri, 2004. Disponível em https://bibliotextos.files.wordpress.com/20I I//2/o-conceito-de-museu-comunitc3a I rio. pdf Acessado em I 3 de janeiro de $20 \mathrm{I} 5$.

LOPES, Maria Margaret. Bertha Lutz e a importância das relações de gênero, da educação e do público nas instituições museais. Musas, n.2, pp.4I-47, 2006.

LORDE, Audre. Sister Outsider: Essaysand Speeches. Berkeley, Crossing Press, 2007. Publicado original em 1984.

LOURO, Guacira Lopes. Gênero, sexualidade e educação. Uma perspectiva pós-estruturalista. Petrópolis:Vozes, 1997.

Um corpo estranho: ensaios sobre a sexualidade e teoria queer. Belo Horizonte: Autêntica, 2004.

MORAES WICHERS, Camila A. Museus comunitários e patrimônio arqueológico: constrangimentos, desafios e possibilidades de diálogo. V Simpósio Internacional de Ciências Sociais, Universidade Federal de Goiás, 2015. Disponível em https://sicsufg.files.wordpress.com/2015//2/wicherscamila-a-moraes-museus-comunitc3al rios-e-patrimc3b4nio-arqueolc3b3 gico-constrangimentos-desafios-e-possibilidades-de-dic 3 a l logo.pdf Acessado em I5 de dezembro de 2018.

MOUTINHO, Mário. Definição evolutiva de Sociomuseologia. Atelier Internacional do MINOM, Lisboa/ Setubal, 2007.

NOCHLIN, Linda. Por que não existiram grandes artistas mulheres? IN: PEDROSA, Adriano \& MESQUITA, André. (Orgs). Histórias da sexualidade: antologia. São Paulo: MASP, pp. I6-37, 20I7. Texto publicado originalmente em 197I.

OLIVEIRA, Ana Cristina Audebert Ramos \& QUEIROZ, Marijara Souza. Museologia substantivo feminino: reflexões sobre museologia e gênero no Brasil. Revista do Centro de Pesquisa e Formação, n 5, pp.6I-77, 2017.

PACHELLA, Luiz. 2015. Obra feminista de Carla Zaccagnini ganha exposição gratuita no MASP.VÁ de Cultura, 20 de novembro de 20I5. Disponível em http://www.vadecultura.com.br/exposicao/obra-feminista-de-carla-zaccagnini-ganha-exposicao-gratuita-no-masp/Acessado em 28 de setembro de 2017.

RECHENA, Aida Maria Dionísio. Sociomuseologia e género: imagens da mulher em exposições de museus portugueses. Tese de Doutoramento, Universidade Lusófona de Humanidades e Tecnologias, 2011.

Revista Memória LGBT.Ano I, Número 0I, 2013.

$\mathrm{RICH}$, Adrienne. 20I0. Heterossexualidade compulsória e existência lésbica. Bagoas, $\mathrm{n}$. 05, pp. 17-44. Publicado original em 1980.

RODRIGUES, Carla. Butler e a desconstrução do gênero. Revista de Estudos Feministas, I3(I): 2I6, pp. I79-383, 2005.

RUBIN, Gayle. O tráfico de mulheres: notas sobre a "economia política" do sexo. IN: 
Museologia, feminismos e suas ondas de renovação

RUBIN, Gayle. Políticas do Sexo. São Paulo: Ubu Editora, pp.9-62. 2017. Publicado Original, 1975.

RÚSSIO, Waldisa. A interdisciplinaridade em Museologia. IN: BRUNO, Maria Cristina Oliveira (org). Waldisa Rússio Camargo Guarnieri: textos e contextos de uma trajetória profissional. São Paulo: Pinacoteca do Estado; Secretaria do Estado da Cultura; Comitê Brasileiro do Conselho Internacional de Museus, pp.123-126, 2010. Publicado original em 1981.

RÚSSIO,Waldisa. Conceito de cultura e sua inter-relação com o patrimônio cultural e a preservação. IN: BRUNO, Maria Cristina Oliveira (org). Waldisa Rússio Camargo Guarnieri: textos e contextos de uma trajetória profissional. São Paulo: Pinacoteca do Estado; Secretaria do Estado da Cultura; Comitê Brasileiro do Conselho Internacional de Museus, pp.203-2I4, 2010. Publicado original em 1984.

SANTOS, Maria Célia Teixeira Moura. Encontros Museológicos - reflexões sobre a museologia, a educação e o museu. Rio de Janeiro: MinC/ IPHAN/ DEMU, 2008.

SANTOS, Myrian Sepúlveda dos. Memória Coletiva e Teoria Social. São Paulo:Annablume, 2012. Publicado original em 2003.

SANTOS, Myrian Sepúlveda dos. Memória coletiva, trauma e cultura: um debate. Revista USP, São Paulo, n. 98, Pp. 5I-68, 2013.

VAQUINHAS, Irene. Museus do feminino, museologia de género e o contributo da história. MIDAS [Online], n.3, pp.I-I5, 2014.

VIDAL Ava. Intersectional feminism'. What the hell is it? (And why you should care). Telegraph, 15/01/2014. Tradução de Bia Cardoso. Disponível em http://blogueirasfeministas.com/2014/07/feminismo-intersecional-que-diabos-e-isso-e-porque-voce-deveria-se-preocupar/ Acessado em 21 de fevereiro de 2018.

WYLIE,Allison.Arqueologia e a crítica feminista da ciência. Entrevista com Alison Wylie. Por Kelly Koide, Mariana Toledo Ferreira \& Marisol Marini. Scientiæsudia, São Paulo, v. I2, n. 3, pp. 549-90, 2014. 